\title{
Genistein induces adipogenesis but inhibits leptin induction in human synovial fibroblasts
}

\author{
Biserka Relic ${ }^{1}$, Mustapha Zeddou' ${ }^{2}$, Aline Desoroux ${ }^{1}, Y_{\text {ves Beguin }}^{2}$, Dominique de Seny ${ }^{1}$ and Michel G Malaise ${ }^{1}$
}

It was shown recently that synovial fibroblast transformation into adipocytes reduced the expression of interleukin-6 (IL-6) and IL-8. However, the synovial fibroblast adipogenesis was inhibited in inflammatory conditions induced by the tumor necrosis factor- $\alpha$ (TNF- $\alpha$ ). Furthermore, adipogenesis is often accompanied by leptin production, a proinflammatory adipokine in rheumatic diseases. In this study, we tested the phytohormone genistein for adipogenic and anti-inflammatory properties on human synovial fibroblasts. Results showed that genistein was able to transform synovial fibroblasts into adipocytes that expressed perilipin-A and produced adiponectin, but not leptin. Furthermore, genistein enhanced glucocorticoid-mediated synovial fibroblast adipogenesis and, in parallel, downregulated glucocorticoid-induced leptin and leptin receptor. Endogenous and TNF- $\alpha$-induced expressions of IL-6, IL-8, p38, p65 and C/EBP- $\beta$ were also downregulated by genistein, showing its anti-inflammatory properties. Peroxisome proliferatoractivated receptor- $\gamma$ (PPAR- $\gamma$ ) agonist, rosiglitazone, had a synergic effect on genistein-induced adipogenesis, whereas the non-active tyrosine kinase inhibitor, daidzein, had a significantly inferior adipogenic activity than genistein. The Janus kinase-2 tyrosine kinase inhibitor, AG 490, mimicked the anti-leptin effect of genistein. These results showed that genistein-induced adipogenesis involves PPAR- $\gamma$ induction and tyrosine kinase inhibition. In conclusion, genistein, alone or coupled with glucocorticoids, have both adipogenic and anti-inflammatory effects on synovial fibroblasts.

Laboratory Investigation (2009) 89, 811-822; doi:10.1038/labinvest.2009.41; published online 11 May 2009

KEYWORDS: adipogenesis; genistein; leptin; peroxisome proliferator-activated receptor- $\gamma$; rheumatoid arthritis; synovial fibroblasts

In rheumatic diseases, such as osteoarthritis (OA) and rheumatoid arthritis (RA), synovial tissue proliferates and becomes the site of inflammation. Synovial proliferation and inflammation lead to chondrocyte apoptosis, cartilage damage and joint dysfunction. ${ }^{1}$ Indeed, cadherin- $11 \mathrm{k} / \mathrm{o}$ mice that form defective synovium are more resistant to experimentally induced arthritis. ${ }^{2}$ Recently, synovial fibroblasts were recognized as multipotent cells that can differentiate into osteocytes, chondrocytes and adipocytes. ${ }^{3-6}$ In addition, synovial fibroblasts were shown to express specific markers of bone marrow-derived multipotent stem cells (MSCs), such as CD-105, CD-90 and CD-73., Among the different sources of MSCs, such as bone marrow, skeletal muscle and adipose tissue, synovium was recognized as a potent source. ${ }^{8}$ Furthermore, synovial MSCs were shown capable of rabbit cartilage repair. ${ }^{9}$ These results indicated that synovium re- presents a precious source of MSCs, and also opened new approaches for combating synovial inflammation, by interfering with signaling pathways involved in MSC differentiation.

Synovial fibroblast transformation into adipocyte-like cells was shown in vitro in the presence of the synthetic peroxisome proliferator-activated receptor- $\gamma$ (PPAR- $\gamma$ ) agonist, troglitazone. ${ }^{6}$ These adipocyte-like cultures expressed less interleukin-6 (IL-6) and IL-8 than control cells, but adipogenesis was inhibited by the tumor necrosis factor- $\alpha$ $(\mathrm{TNF}-\alpha)$, suggesting that in inflammatory conditions, cells may continue to produce high levels of IL-6 and IL-8. In addition, adipogenesis is associated with the production of leptin, an adipokine thought to be proinflammatory in both OA and RA. ${ }^{10-13}$ To that purpose, we searched for the PPAR$\gamma$ agonist(s) having anti-inflammatory properties in the

\footnotetext{
${ }^{1}$ Department of Rheumatology, GIGA-Research, University of Liège, CHU de Liège, Liège, Belgium and ${ }^{2}$ Department of Haematology, GIGA-Research, University of Liège, $\mathrm{CHU}$ de Liège, Liège, Belgium

Correspondence: Dr MG Malaise, MD, PhD, Department of Rheumatology, GIGA-Research, CHU de Liège, B4000 Liège, Belgium.

E-mail: Michel.Malaise@ulg.ac.be

Received 2 October 2008; revised 3 March 2009; accepted 4 March 2009
} 
presence of TNF- $\alpha$. Three PPAR- $\gamma$ agonists were tested, namely the synthetic rosiglitazone, the precursor of natural PPAR- $\gamma$ agonist 15d-PGJ2, prostaglandin D2 (PGD2) and the plant hormone, genistein. ${ }^{14,15}$ The results showed that TNF- $\alpha$-stimulated synovial fibroblast cultures expressed high levels of IL-6 and IL-8, treated with PGD2 or not. However, we showed that genistein downregulated both endogenous and TNF- $\alpha$-induced IL- 6 and IL- 8 in synovial fibroblasts. Rosiglitazone was also able to downregulate TNF- $\alpha$-induced IL-6, but significantly less than genistein.

We also showed that genistein, alone or in concerted action with rosiglitazone or glucocorticoids, induced synovial fibroblast adipogenesis. Furthermore, we observed that despite their ability to downregulate TNF- $\alpha$-induced IL-6 and IL-8, glucocorticoids induced marked leptin and leptin receptor expression in synovial fibroblasts. Genistein downregulated glucocorticoid-induced leptin and leptin receptor expression. As leptin has been recognized as proinflammatory for rheumatic diseases, ${ }^{10,11}$ these results suggest that concomitant application of genistein and glucocorticoids may promote their anti-inflammatory properties.

\section{MATERIALS AND METHODS Synovial Fibroblast Isolation, Cell Culturing and Adipogenesis Induction}

The synovial tissue was obtained from OA, RA and traumatic patients not having rheumatoid diseases, during joint replacement. Informed consents were obtained, and experiments were approved by the ethics committee of our academic hospital (CHU, Liège, Belgium). Synovial fibroblasts were isolated as explained earlier. ${ }^{16}$ Cells were cultured in the DMEM medium (Cambrex Bio Science, Walkersville, MD, USA), with L-glutamine (2 mM), streptamycin (100 mg/ $\mathrm{ml}$ ) and penicillin $(100 \mathrm{U} / \mathrm{ml})$ (BioWhittaker, Walkersville, MD, USA), and supplemented with $10 \%$ fetal bovine serum (Lonza, Basel, Switzerland) for at least three passages before being used. Experiments were carried out in the DMEM medium lacking phenol red (Cambrex Bio Science), supplemented with $10 \%$ charcoal-stripped fetal bovine serum. Cells $\left(5 \times 10^{4} / 0.5 \mathrm{ml}\right.$ of medium) were seeded in 24 -well plates (BD Biosciences, San Jose, CA, USA) in triplicate. On the second day of culture, cells were stimulated with rosiglitazone, genistein, SB 203580, tyrphostin AG 490 (Alexis Corp., San Diego, CA, USA), PGD2 (Cayman Chemical, Ann Arbor, MI, USA) and/or dexamethasone, prednisolone, cortisone, 17 - $\beta$-estradiol, $N$-acetyl cysteine (NAC) or daidzein (SigmaAldrich, St Louis, MI, USA), in the presence or absence of TNF- $\alpha$. The medium was changed and cells were re-stimulated every 6 days. Cells were harvested after 1-4 weeks. The synovial fibroblast origins used for experiments were Figure 1a: OA patient, Figure 1b: traumatic patient, Figure 2a-d: RA patient, Figure 2e: traumatic patient, Figure 2f: OA patient, Figure 3a: RA patient, Figure 3b: Patient 1: traumatic, Patient 2: OA, Patient 3: RA, Patient 4:OA. Figures 4 and 5:
OA patients, Figure 6a-d: OA patient, Figure 6e: OA patient, Figure 6f: RA patient, Figures 7-9: OA patients.

\section{Oil Red Staining}

Cells were fixed in 4\% paraformaldehyde in PBS for $15 \mathrm{~min}$ and then washed with PBS. For staining, an oil red stock solution ( $5 \mathrm{~g} / \mathrm{l}$ of isopropanol) was diluted with distilled water in a 4:6 ratio. Staining was performed for at least $1 \mathrm{~h}$ at room temperature. Before microscopy, cells were washed with distilled water.

\section{Microscopy}

Photos were captured using a digital sight camera (2 MV) under the inverted microscope Eclipse TS100 (Nikon Instruments Inc., Melvile, NY, USA), using NIS-Elements Basic Research software (Nikon Instruments Inc.) and objectives with phase contrast.

\section{ELISA}

Protein concentrations were determined in the cell supernatant using commercial kits IL-6, IL-8 (BioSource, Fleurus, Belgium), leptin and adiponectin (R\&D Systems, Minneapolis, MN, USA) according to the manufacturer's instructions.

\section{Western Blot}

Cells were collected, lysed and total proteins separated by SDS-PAGE as explained earlier. ${ }^{16}$ Membranes were incubated with perilipin-A (Sigma-Aldrich), PPAR- $\gamma$ (E-8), ERK1 (K-23), p-ERK (E-4), C/EBP- $\beta$ (D198), Ob-R (B-3) (Santa Cruz Biotechnology, Santa Cruz, CA, USA), p38, p38 Thr80/Tyr82 (Cell Signaling, Beverly, MA, USA) and NF- $\kappa$ B p65 (Upstate Biology, Lake Placid, NY, USA) antibodies for $1-3 \mathrm{~h}$ at room temperature. Western blots were shown with 1:2000 diluted anti-mouse or anti-rabbit (DAKO A/S, Glostrup, Denmark) antibodies and ECL chemiluminescent reagents (Amersham Biosciences, Little Chalfont, Buckinghamshire, UK).

\section{Flow Cytometry Analyses}

Simple staining was performed with fluorescent-conjugated antibodies. The following monoclonal, PE-conjugated antibodies were used: anti-CD-73, anti-CD-90, anti-105, antiHLA-DR, anti-CD-80 and anti-CD-45 (BD Biosciences). The phenotype was performed on $(1-5) \times 10^{5}$ synovial fibroblasts, cultured earlier for three passages. The fluorescence intensity was analyzed on FACSvantage with Cell Quest software (BD Biosciences).

\section{Chip (Chromatin Immunoprecipitation) Assay}

Chip (chromatin immunoprecipitation) assay was performed on the basis of $\mathrm{Q}^{2} \mathrm{ChIP}$ protocol and The Low Cell ChIP Kit (Diagenode, Liege, Belgium), ${ }^{17}$ with a few modifications. Synovial fibroblasts were seeded $24 \mathrm{~h}$ before the experiment in $10-\mathrm{cm}$ dishes $\left(1.5 \times 10^{6} / 5 \mathrm{ml}\right)$. The next day, cells were treated with genistein for $3 \mathrm{~h}$, followed by $15 \mathrm{~min}$ of TNF- $\alpha$ stimulation. Protein DNA cross-linking was performed 

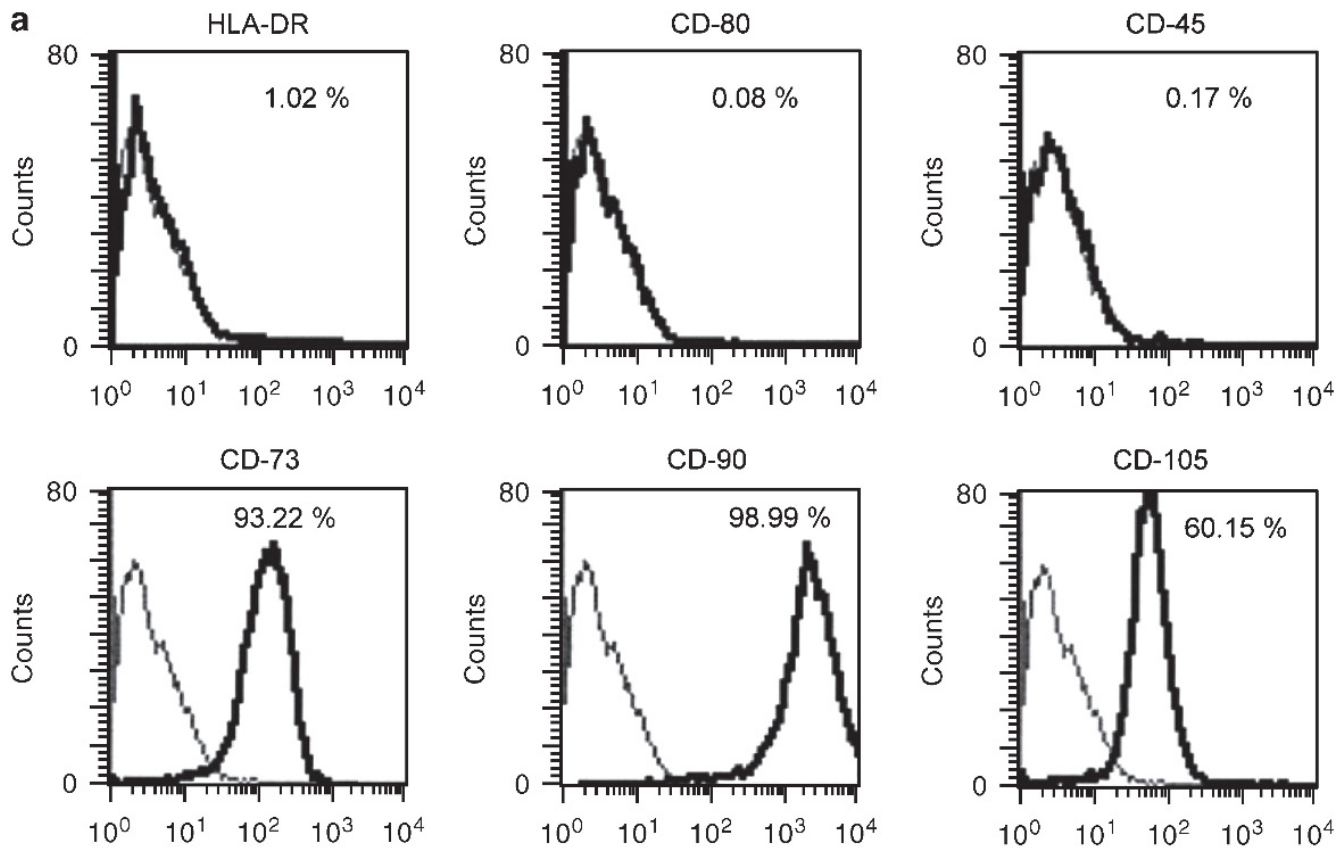

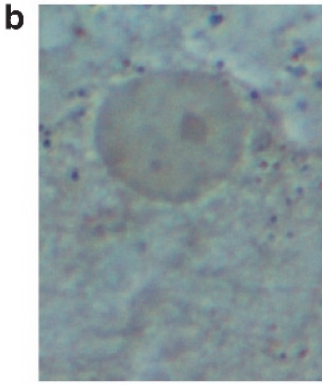

Control

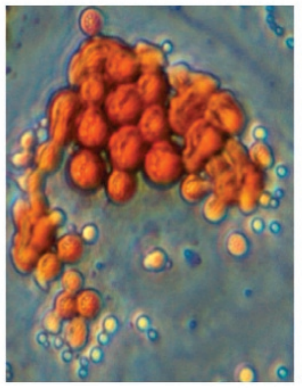

Rosiglitazone

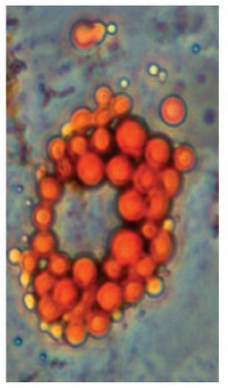

Genistein

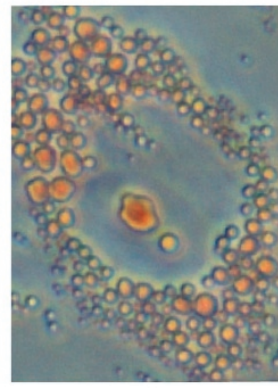

PGD2

Figure 1 Genistein, rosiglitazone and PGD2 induce synovial fibroblasts adipogenesis. (a) Flow cytometry diagrams showing the expression profile of synovial fibroblasts harvested after three passages and stained for surface molecules as indicated. The percentage of positive cells was calculated and shown in each diagram. (b) Oil-red-stained adipocyte-like single cell in the 3-week-old synovial fibroblast cultures treated with different PPAR- $\gamma$ agonists only as indicated. Photos were taken under an inverse microscope at magnification $\times 40$.

directly in the culture medium with $1 \%$ formaldehyde, at $37^{\circ} \mathrm{C}$, for $10 \mathrm{~min}$. After being washed thrice with cold PBS containing complete protease inhibitor cocktail (Roche, Mannheim, Germany), cells were scraped on ice, recuperated by centrifugation ( 1500 r.p.m., $10 \mathrm{~min}, 4^{\circ} \mathrm{C}$ ) and dissolved in $130 \mu \mathrm{l}$ of lysis buffer (50 mM TRIS-HCl, pH8, $10 \mathrm{mM}$ EDTA, $1 \%$ SDS, $1 \mathrm{mM}$ PMSF and protease inhibitor cocktail). Sonication was performed for $3 \mathrm{~min}$, with 30 -s pauses, using the maximum power of Bioruptor (Diagenode). Chromatin was diluted with $870 \mu$ l RIPA buffer ( $10 \mathrm{mM}$ Tris- $\mathrm{HCl}, \mathrm{pH} 7.5$, 1 mM EDTA, 1\% Triton X-100, 0.1\% SDS, Na-deoxycholate, $100 \mathrm{mM} \mathrm{NaCl}$ ), centrifuged for $5 \mathrm{~min}$ at 12000 r.p.m. and supernatant recuperated. For immunoprecipitation, $100 \mu \mathrm{l}$ of diluted chromatin was incubated overnight $\left(4^{\circ} \mathrm{C}\right.$, at 20 r.p.m.) in $0.2-\mathrm{ml}$ tubes with $10 \mu \mathrm{l}$ of magnetic protein $\mathrm{A}$ beads (Dynabeads, Invitrogen, Carlsbad, CA, USA) that had been pre-covered for at least $2 \mathrm{~h}$ with NF- $\kappa \mathrm{B}$ p65 (A) $\mathrm{X}$ (Santa Cruz) or C/EBP- $\beta$ (LAP) (Cell Signaling) antibodies. IgG antibodies were used for the negative control. Beads were washed thrice with RIPA buffer, dissolved in TE buffer (10 mM Tris- $\mathrm{HCl}, \mathrm{pH} 8,10 \mathrm{mM}$ EDTA) and transferred into Eppendorf tubes. TE was discarded and DNA was purified by boiling the beads for $10 \mathrm{~min}$ with $100 \mu \mathrm{l}$ of $10 \%$ Chelex-100 slurry (Bio Rad, Hercules, CA, USA), $1 \mathrm{~h}$ of proteinase-K treatment $(200 \mu \mathrm{g} / \mathrm{ml})$ at $55^{\circ} \mathrm{C}$, followed by $10 \mathrm{~min}$ of sample boiling. DNA containing supernatant was recuperated and used for PCR analyses. Input DNA was purified in the same way from the $100 \mu \mathrm{l}$ of starting material used for immunoprecipitation. Standard and real-time PCR were performed using the following IL-8 promoter primer pairs: 5'-GGCCATCAGTTGCAAATCG-3' (forward) and anti-sense 5'-AGTGCTCCGGTGGCTTTTT-3' (reverse). Real-time PCR 


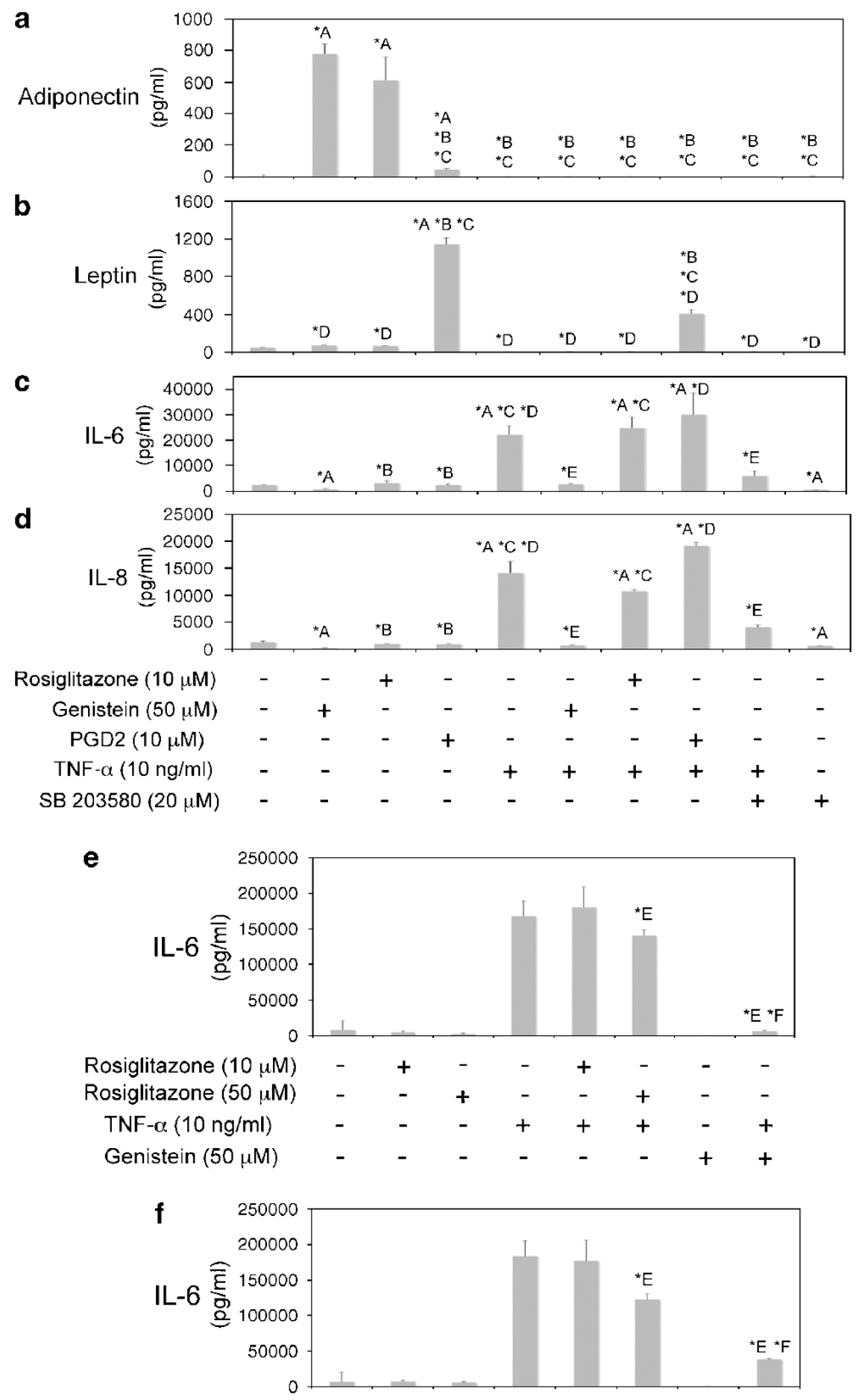

Figure 2 Genistein inhibits TNF- $\alpha$-induced IL- 6 and IL-8. (a-f) ELISA measured adiponectin (panel a), leptin (panel b), IL-6 (panels c, e and f) and IL-8 (panel d) production in cell supernatant. Synovial fibroblasts, obtained from RA (panels a-d), traumatic (panel e) or OA (panel f) patient, were treated for 3 weeks with different PPAR- $\gamma$ agonists or $\mathrm{p} 38$ inhibitor, SB 203580, in the presence or absence of TNF- $\alpha$, as indicated. ${ }^{*}$, statistically different from control cells; ${ }^{\star} B$, statistically different from genistein-treated cells; ${ }^{*} C$, statistically different from rosiglitazone-treated cells; ${ }^{\star} D$, statistically different from $P G D 2$-treated cells; ${ }^{\star} E$, statistically different from TNF- $\alpha$-treated cells; ${ }^{*}$, statistically different from TNF- $\alpha$ - and rosiglitazone-treated cells.

was performed in triplicate using the SYBR green PCR mix (Applied Biosystems) and the ABI Prism 7000 Sequence Detection System (ABI Prism, Foster City, CA, USA).

\section{Statistics}

$P$-values were obtained using the Mann-Whitney $U$-test and were considered as significant when $<0.05$. 


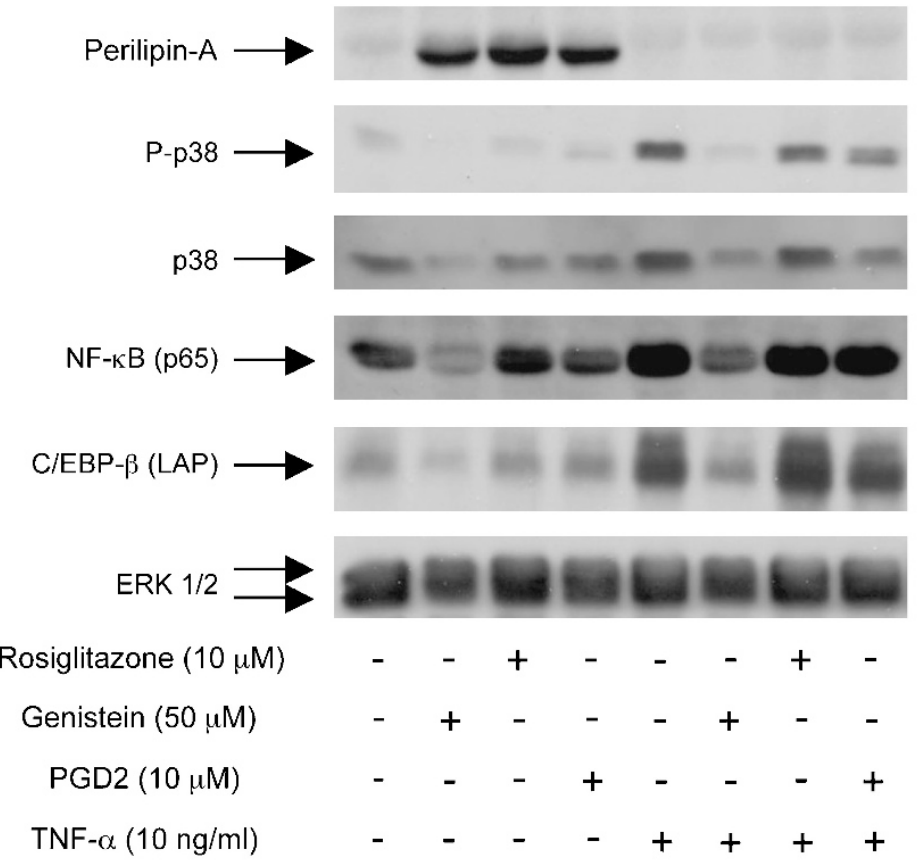

b

Genistein ( 3 hours)
TNF- $\alpha$ ( 15 minutes)
IP: IgG
IP: $p 65$
IP: C/EBP- $\beta$
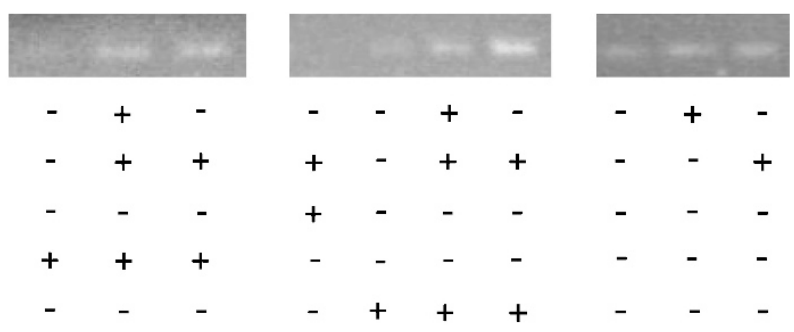

C

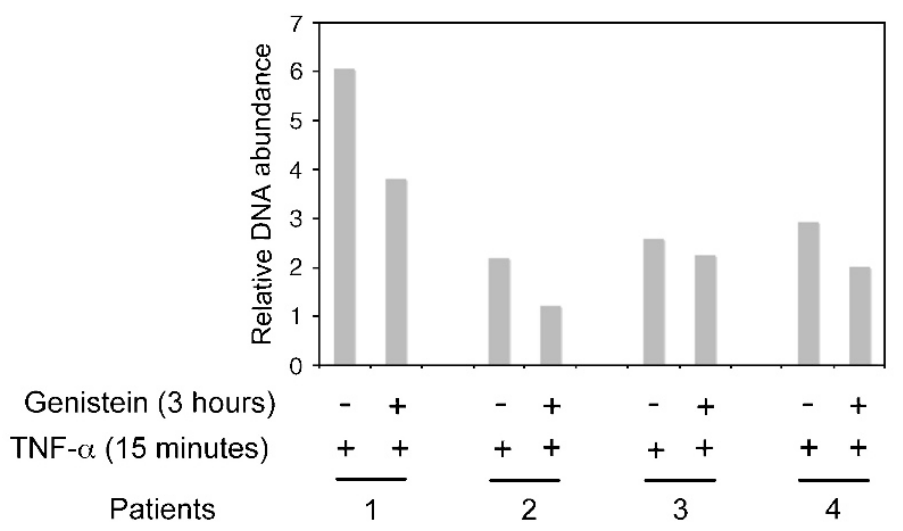

Figure 3 Genistein inhibits $p 38, C / E B P$ and NF- $\kappa$ B pathways. (a) Western blots showing expression of adipocyte marker, perilipin-A, phosphorylated p38 (Pp38), p38, p65 units of NF- $\kappa$ B and LAP form of C/EBP- $\beta$ in synovial fibroblasts extracts. Cells were treated for 4 weeks with different PPAR- $\gamma$ agonists, in the presence or absence of TNF- $\alpha$, as indicated. ERK $1 / 2$ expression was used as control. (b and $\mathbf{c}$ ) ChIP analyses performed with p65 or C/EBP- $\beta$ antibodies on the synovial fibroblast pre-treated with genistein or not $(50 \mu \mathrm{M})$, then $15 \mathrm{~min}$ of TNF- $\alpha(10 \mathrm{ng} / \mathrm{ml})$ treatment. DNA was amplified by standard (panel b) or real-time PCR (panel c) with IL-8 promoter primers. Input DNA was diluted in a ratio of 1:10. IgG antibodies were used as negative control.

\section{RESULTS}

Genistein Induces Synovial Fibroblast Adipogenesis and Downregulates both Endogenous and TNF- $\alpha$-Induced IL-6 and IL-8

Isolated human synovial fibroblasts that were cultured earlier for at least three passages were used. FACS analyses con- firmed that synovial fibroblasts expressed mesenchymal stem cell markers, CD-73, CD-90 and CD-105 (Figure 1a). Cells were negative for HLA-DR, CD-80, CD-45 (Figure 1a), as well as for CD-3 and CD-31 (data not shown). Synovial fibroblasts were stimulated with genistein, rosiglitazone or PGD2 in the presence or absence of TNF- $\alpha$ for 3-4 weeks. 


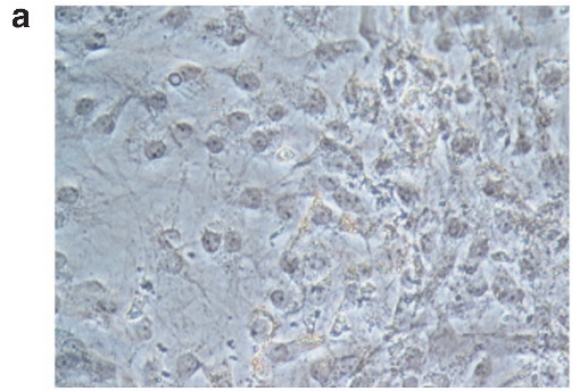

Control

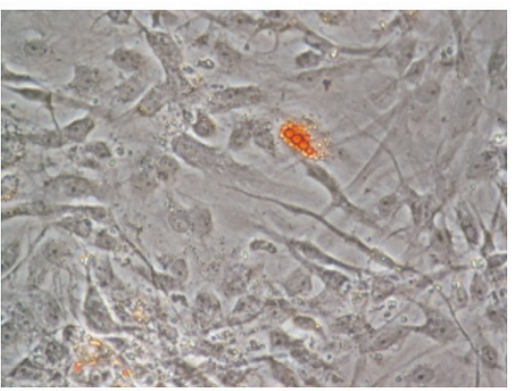

Genistein $(100 \mu \mathrm{M})$

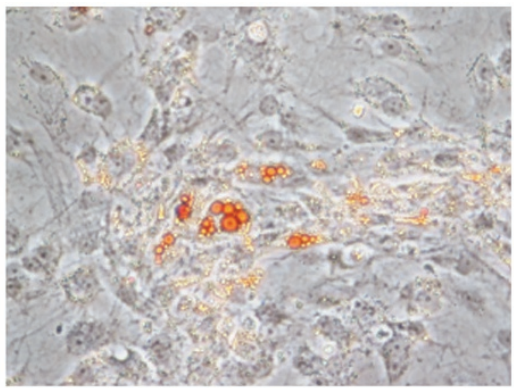

Genistein $(25 \mu \mathrm{M})$

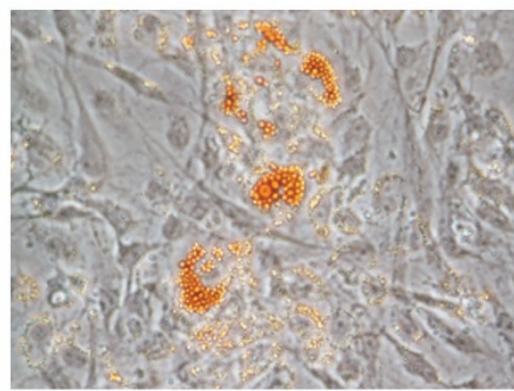

Rosiglitazone $(10 \mu \mathrm{M})$

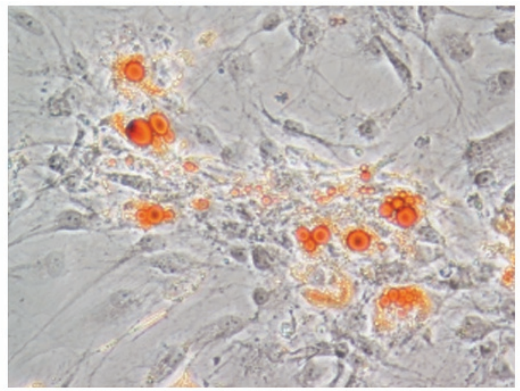

Genistein $(50 \mu \mathrm{M})$

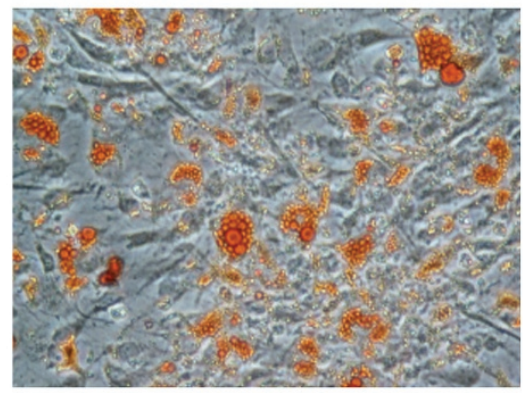

Genistein $(50 \mu \mathrm{M})$ and

Rosiglitazone $(10 \mu \mathrm{M})$

b
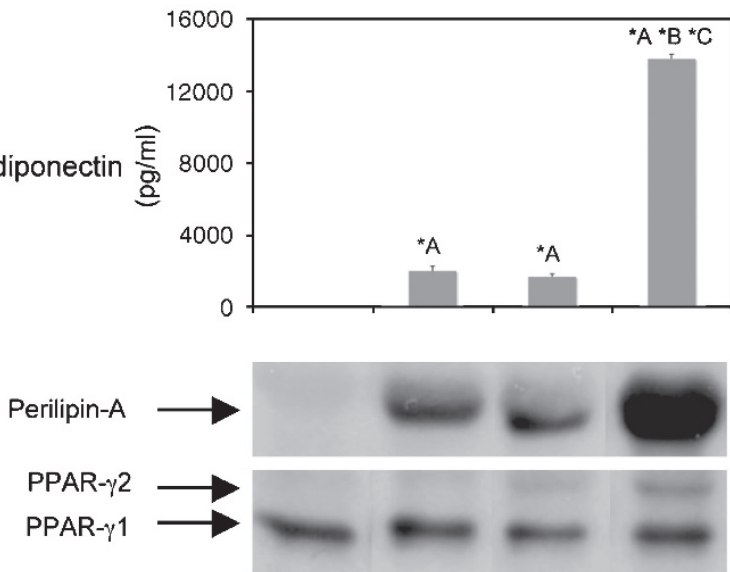

ERK 1/2

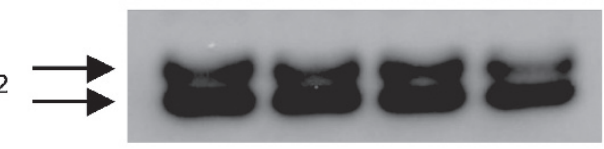

Rosiglitazone $(10 \mu \mathrm{M})$

Genistein $(50 \mu \mathrm{M})$

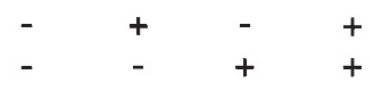

Figure 4 Genistein and rosiglitazone induce adipogenesis in synergism. (a-c) Synovial fibroblasts were cultured with genistein or rosiglitazone only, or both substances simultaneously, at indicated concentrations, for 4 weeks. (Panel a) Oil-red-stained cells. Photos were taken under an inverse microscope at magnification $\times 20$. (Panel b) ELISA measured adiponectin production in cell supernatant. ${ }^{\star} A$, statistically different from control cells; ${ }^{*} B$, statistically different from genistein-treated cells; ${ }^{*}$ C, statistically different from rosiglitazone-treated cells. (Panel c) Western blots showing perilipin-A and PPAR- $\gamma$ expressions. ERK 1/2 expression was used as control.

Adipocyte-like cells (Figures $1 \mathrm{~b}$ and $4 \mathrm{a}$ ) that produced adiponectin (Figure 2a) emerged in cultures treated with genistein or rosiglitazone. These fat droplets stained positively with oil red (Figures $1 \mathrm{~b}$ and $4 \mathrm{a}$ ) and did not produce leptin (Figure 2b). PGD2 induced mainly sebum-like droplets
(Figure 1b) and small amounts of adiponectin (Figure 2a) and leptin (Figure 2b). Both kinds of droplets expressed perilipin-A, inhibited by TNF- $\alpha$ (Figure 3). TNF- $\alpha$ also inhibited genistein- and rosiglitazone-induced adiponectin production, as well as PGD2-induced leptin production 

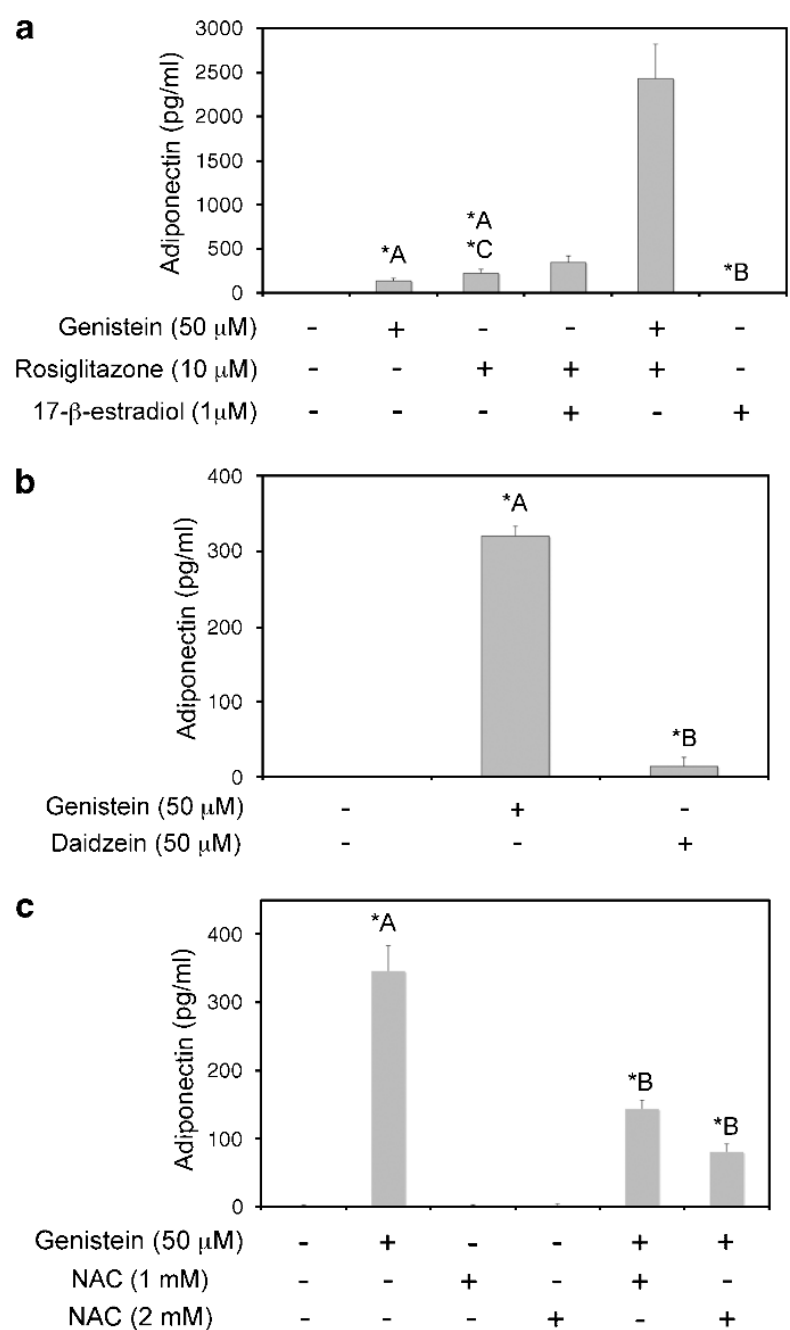

Figure 5 Effects of $17-\beta$-estrogen, daidzein and $N$-acetyl cysteine (NAC) on synovial fibroblast adipogenesis. (a-c) ELISA measured adiponectin production in cell supernatant. (Panel a) Synovial fibroblasts were treated for 4 weeks with genistein, rosiglitazone or simultaneously with rosiglitazone and 17- $\beta$-estrogen, or rosiglitazone and genistein, at indicated concentrations. ${ }^{\star} A$, statistically different from control cells; ${ }^{\star} B$, statistically different from genistein-treated cells; ${ }^{\star} C$, statistically different from rosiglitazone- and genistein-treated cells. (Panel b) Synovial fibroblasts were treated for 4 weeks with genistein or daidzein. ${ }^{\star} A$, statistically different from control cells; ${ }^{\star} B$, statistically different from genistein-treated cells. (Panel c) Synovial fibroblasts were treated for 3 weeks with genistein, NAC or simultaneously with genistein and NAC. ${ }^{\star} A$, Statistically different from control cells; ${ }^{\star} B$, statistically different from genistein-treated cells.

(Figure $2 \mathrm{a}$ and $\mathrm{b}$ ). Genistein, but not rosiglitazone or PGD2, at commonly used concentrations $(10 \mu \mathrm{M})$, downregulated both endogenous and TNF- $\alpha$-induced production of IL-6 and IL-8 (Figure $2 \mathrm{c}$ and $\mathrm{d}$ ). However, at high concentrations, rosiglitazone $(50 \mu \mathrm{M})$ also downregulated TNF- $\alpha$-induced IL-6 production, but its effect was statistically inferior compared with that of genistein (Figure 2e and f). High concentrations of PGD2 could not be tested because they induced synovial fibroblast death (results not shown). The genistein effect was mimicked partially by p38 inhibitor, SB
203580, suggesting that genistein effect may involve p38. Similar results were obtained with synovial fibroblasts originating from the synovium of RA (Figure $2 \mathrm{a}-\mathrm{d}$ ), OA (Figure 2f) or traumatic patients (Figure 2e). These results showed that genistein has both adipogenic and anti-inflammatory effects on synovial fibroblasts.

\section{Genistein Inhibits Endogenous and TNF- $\alpha$-Induced p38, C/EBP and NF- $\kappa$ B Pathways}

As both genistein and p38 inhibitor, SB203580, inhibited endogenous and TNF- $\alpha$-induced synovial fibroblasts IL-6 and IL- 8 production (Figure $2 \mathrm{c}$ and $\mathrm{d}$ ), and because promoters of IL- 6 and IL- 8 have binding sites for both C/EBP- $\beta$ and NF- $\kappa \mathrm{B},{ }^{18,19}$ we have tested the effect of TNF- $\alpha$ and PPAR- $\gamma$ agonists on the expression of these proteins in synovial fibroblasts. Western blots showed that TNF- $\alpha$ induced phosphorylation of $\mathrm{p} 38$, and expression of $\mathrm{p} 38, \mathrm{C} / \mathrm{EBP}-\beta$ and p65 unit of NF- $\kappa \mathrm{B}$ (Figure 3). Genistein, but not the commonly used concentrations $(10 \mu \mathrm{M})$ of rosiglitazone or PGD2, downregulated TNF- $\alpha$-induced p38 phosphorylation and both endogenous and TNF- $\alpha$-induced p38, C/EBP- $\beta$ and p65 (Figure 3).

Genistein has been shown earlier not to change TNF- $\alpha$ induced p65/DNA binding but to inhibit NF- $\kappa$ B transactivation. $^{20}$ Our results, obtained by the ChIP assay, also showed that genistein did not prevent TNF- $\alpha$-induced binding of p65 to IL-8 (Figure 3b). However, genistein prevented C/EBP- $\beta$ binding to IL-8 (Figure $3 \mathrm{~b}$ ) and IL-6 promoters (results not shown). These results suggested that genistein inhibition of TNF- $\alpha$-induced IL- 6 and IL- 8 production involves C/EBP- $\beta$ transcription factor.

\section{Genistein and Rosiglitazone Induce Synovial Fibroblast Adipogenesis in Synergism}

Genistein was shown to be a PPAR- $\gamma^{14}$ and estrogen receptor $(\mathrm{ER})^{15}$ inducer, as well as an inhibitor of protein tyrosine kinases. $^{21}$ To test the involvement of PPAR- $\gamma$ in genisteininduced adipogenesis, cells were treated simultaneously with genistein and synthetic PPAR- $\gamma$ agonist, rosiglitazone. Compared with cultures treated with genistein and rosiglitazone alone, the numbers of oil-red-stained droplets in combined cultures were increased markedly (Figure 4a). Moreover, ELISA and western blots showed that the expression of adipocyte-specific markers, adiponectin and perilipin-A, were both markedly increased when genistein and rosiglitazone were applied simultaneously (Figure $4 \mathrm{~b}$ and c). The expression of PPAR- $\gamma 2$ also increased when both agonists were applied simultaneously (Figure 4c). These results suggested that genistein and rosiglitazone act in synergism on synovial adipogenesis through the PPAR- $\gamma$ pathway.

To test the involvement of ERs on synovial fibroblast adipogenesis, cells were treated with 17- $\beta$-estradiol, which did not induce synovial fibroblast adipogenesis and did not significantly affect rosiglitazone-induced adipogenesis (Figure 5a). 

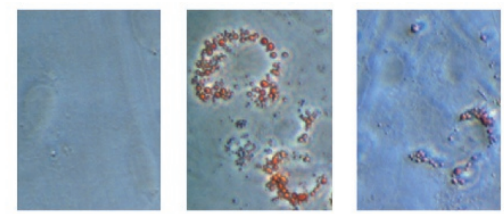

b
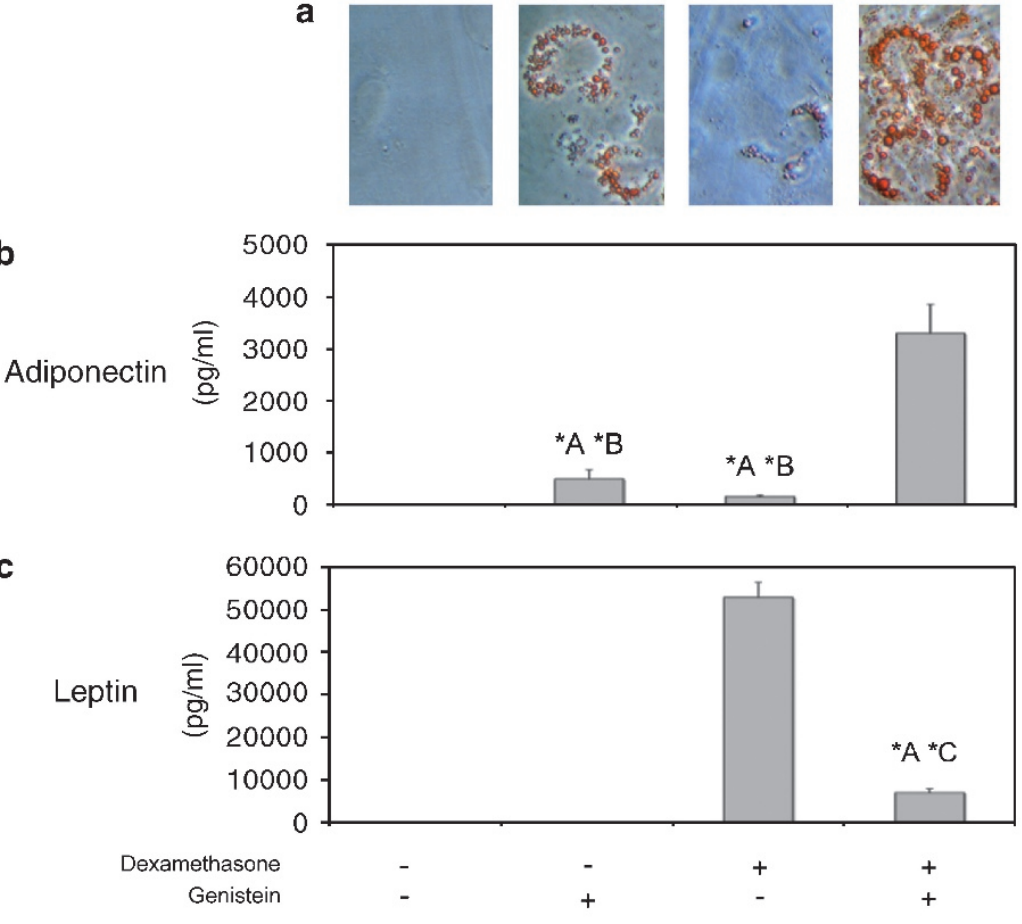

d

(

e

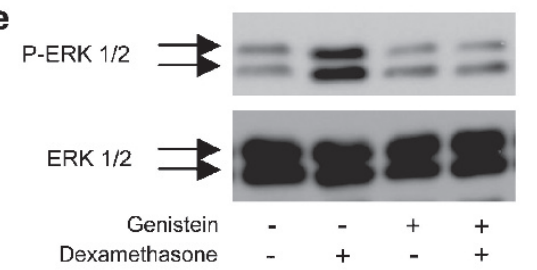

f

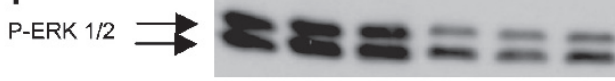

ERK 1/2

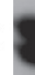

Genistein

Dexamethasone

Cortisone

Figure 6 Genistein downregulates dexamethasone-induced leptin and its receptor and ERK1/2 phosphorylation. (a-d) Synovial fibroblasts were cultured in the presence of genistein $(50 \mu \mathrm{M})$ or dexamethasone $(1 \mu \mathrm{M})$ or both substances simultaneously, for 4 weeks. (Panel a) Oil-red-stained cells. Photos were taken under an inverse microscope at magnification $\times 40$. (Panel b) ELISA measured adiponectin production in cell supernatant. (Panel c) ELISA measured leptin production in cell supernatant. ${ }^{*} A$, statistically different from control cells; ${ }^{*} B$, statistically different from genistein- and dexamethasone-treated cells; ${ }^{*}$ C, statistically different from dexamethasone-treated cells. (Panel d) Western blot showing leptin receptor (Ob-R) expression. ERK 1/2 expression was used as control. (e and f) Synovial fibroblasts were cultured in the presence of genistein $(50 \mu \mathrm{M})$, or glucocorticoid $(1 \mu \mathrm{M})$ or both substances simultaneously, for 4 weeks. Synovial fibroblast were provided by OA (panel e) and RA (panel f) patients. Western blots are showing ERK1/2 phosphorylation. ERK 1/2 expression was used as control.

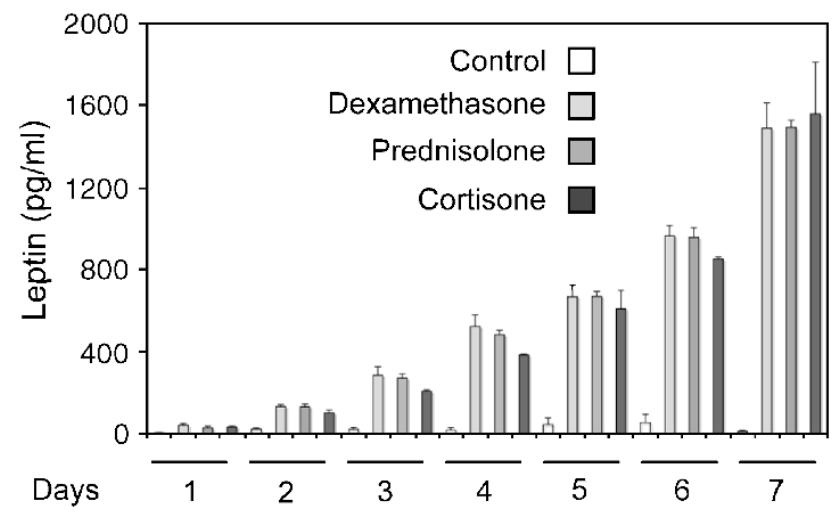

Figure 7 Glucocorticoids induce rapid leptin production in synovial fibroblasts. ELISA measured leptin production in cell supernatant. Synovial fibroblasts were cultured in the presence of dexamethasone $(1 \mu \mathrm{M})$, prednisolone $(1 \mu \mathrm{M})$ or cortisone $(1 \mu \mathrm{M})$ for the time indicated.

The involvement of protein tyrosine kinase inhibition on genistein-induced adipogenesis was tested using the genistein non-active analog, daidzein. Although daidzein was able to induce some fat droplets in synovial fibroblasts (results not shown), its effect on adiponectin production was negligible compared with genistein (Figure $5 b$ ). These results suggested that, in addition to PPAR- $\gamma$, genistein-induced adipogenesis involves tyrosine kinase inhibition.

The involvement of anti-oxidant effects on genistein-induced adipogenesis was tested using NAC, which when applied alone, did not have an adipogenic effect on synovial fibroblasts (Figure 5c). Furthermore, it significantly inhibited genisteininduced adipogenesis (Figure $5 \mathrm{c}$ ), suggesting that genistein-induced adipogenesis does not involve its anti-oxidant properties.

\section{Genistein Downregulates Glucocorticoid-Induced Leptin Production}

Glucocorticoids are widely used for the treatment of rheumatic diseases and are also known to be adipogenic in vivo and in vitro. Surprisingly, dexamethasone alone induced adipogenic transformation of only a few synovial fibroblasts and small amount of adiponectin (Figure 6a and b, respectively) but markedly induced leptin production (Figure 6c) and leptin receptor (Ob-R) expression (Figure 6d). Leptin production was already detected after $48 \mathrm{~h}$ of dexamethasone 

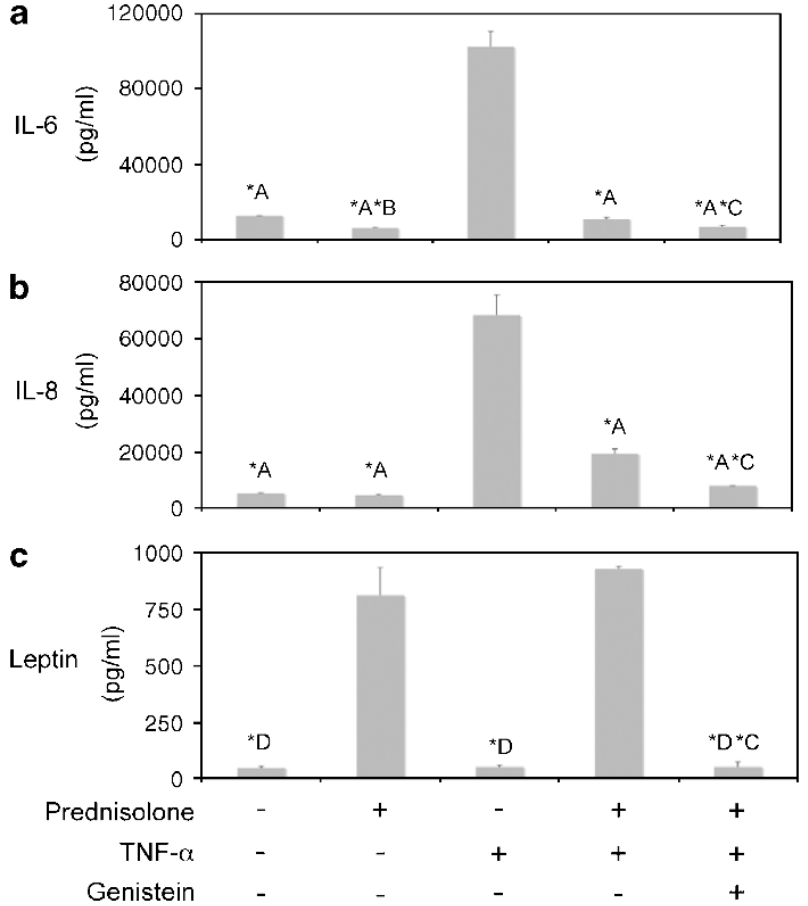

Figure 8 Genistein downregulates glucocorticoid-induced leptin in the presence of TNF- $\alpha$. $(\mathbf{a}-\mathbf{c})$ Synovial fibroblasts were stimulated with prednisolone $(1 \mu \mathrm{M})$ in the presence or absence of TNF- $\alpha(10 \mathrm{ng} / \mathrm{ml})$ or TNF$\alpha$ and genistein $(50 \mu \mathrm{M})$, for 1 week. ELISA measured (panel a) IL-6, (panel b) IL-8 and (panel c) leptin production in cell supernatant. ${ }^{\star} \mathrm{A}$, statistically different from TNF- $\alpha$-treated cells; ${ }^{*} B$, statistically different from control cells; ${ }^{*} C$, statistically different from TNF- $\alpha$ - and prednisolone-treated cells; ${ }^{\star} D$, statistically different from prednisolone-treated cells.

treatment and increased daily (Figure 7). Similar results were obtained with prednisolone and cortisone (Figure 7). Genistein markedly enhanced dexamethasone-induced adipogenesis (Figure $6 \mathrm{a}$ and b). Of interest, in parallel, genistein downregulated dexamethasone-induced leptin production (Figure 6c) and leptin receptor expression (Figure 6d). Furthermore, genistein was able to downregulate glucocorticoid-induced leptin in the presence of TNF- $\alpha$ (Figure 8c). In addition, genistein combined with prednisolone further inhibited TNF- $\alpha$-induced IL- 6 and IL- 8 compared with prednisolone alone (Figure $8 \mathrm{a}$ and $\mathrm{b}$, respectively). Genistein also downregulated both endogenous and glucocorticoid-induced ERK1/2 phosphorylation (Figure 6e and $\mathrm{f}$ ). Inhibitor of the Janus kinase-2 (JAK-2) tyrosine kinase, tyrphostin AG 490, but not the commonly used concentration of PPAR- $\gamma$ agonist, rosiglitazone $(10 \mu \mathrm{M})$, (results not shown), inhibited prednisolone-induced leptin (Figure 9a). Moreover, western blot showed an increased tyrosine phosphorylation in the extract of dexamethasoneand prednisolone-treated synovial fibroblasts (Figure 9b). Genistein inhibited dexamethasone- and prednisolone-induced tyrosine phosphorylation (Figure 9b). These results suggested that genistein anti-leptin effect mainly involves tyrosine kinase inhibition.
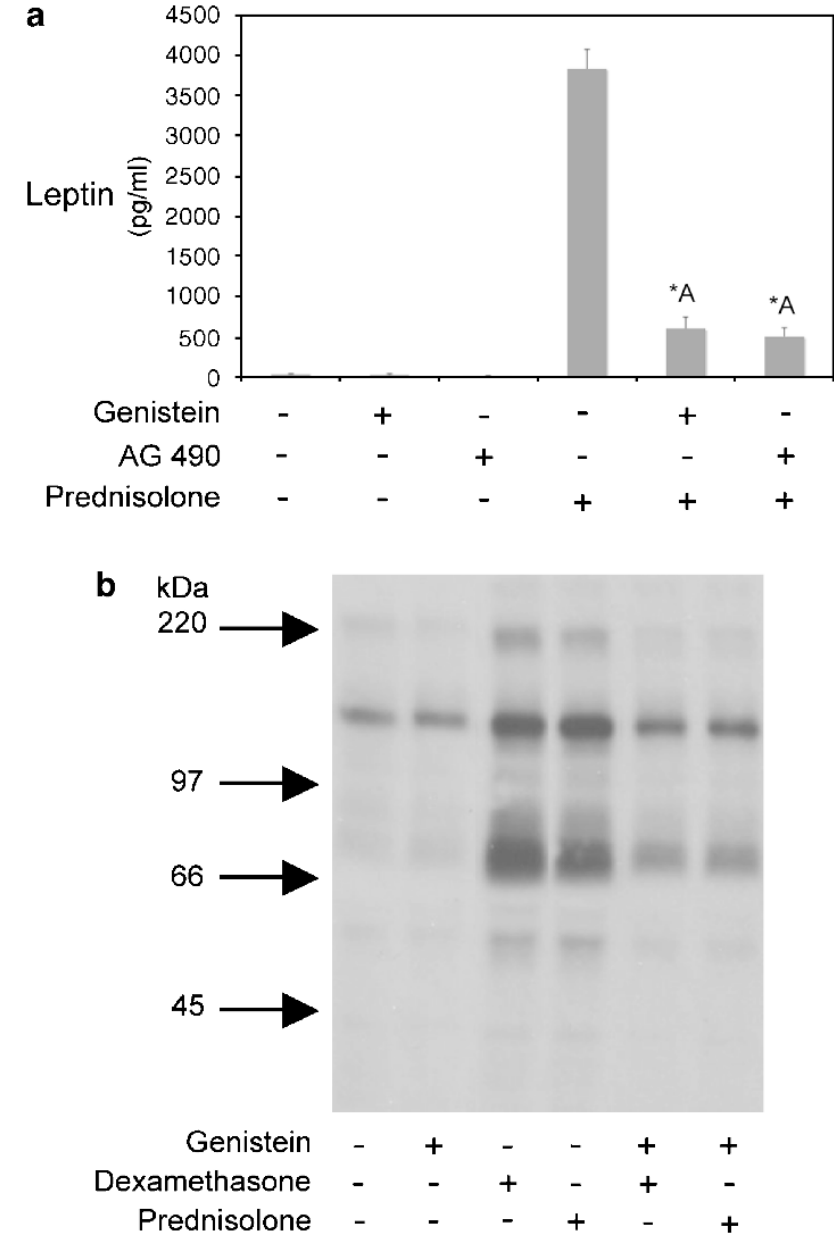

Figure 9 JAK-2 tyrosine kinase inhibitor mimics the anti-leptin effect of genistein and genistein inhibits prednisolone-induced tyrosine phosphorylation. (a) Synovial fibroblasts were stimulated with genistein $(50 \mu \mathrm{M})$ or JAK-2 inhibitor tyrphostin AG $490(50 \mu \mathrm{M})$ in the presence or absence of prednisolone $(1 \mu \mathrm{M})$ for 1 week. ELISA measured leptin production in cell supernatant. ${ }^{\star} A$, statistically different from prednisolonetreated cells. (b) Synovial fibroblasts were stimulated with genistein $(50 \mu \mathrm{M})$, dexamethasone $(1 \mu \mathrm{M})$, prednisolone $(1 \mu \mathrm{M})$ or with genistein and each glucocorticoid simultaneously for 3 weeks. Western blot shows tyrosine phosphorylation in total synovial fibroblast extracts. ERK 1/2 expression was used as control.

\section{DISCUSSION}

Very recently, synovial fibroblasts were recognized as multipotent mesenchymal stem cells that express stem cell markers ${ }^{3,7}$ and can differentiate into chondrocytes, osteoblasts and adipocytes. ${ }^{3-6}$ Usually, synovial fibroblast adipogenesis was induced using a mixture of substances, including methyl-isobutylxanthine and indomethacine $e^{5}$ or insulin, dexamethasone and troglitazone. ${ }^{4,6}$ These adipocyte-like cultures $^{4,6}$ expressed to a lesser degree the proinflammatory cytokines, IL-6 and IL-8, and the adipogenesis of synovial fibroblasts has been proposed as an anti-inflammatory tool for combating rheumatoid diseases. ${ }^{6}$ However, the same work showed that TNF- $\alpha$ inhibited synovial fibroblast adipogenesis, 
suggesting limiting effects of adipogenic substances in inflammatory conditions. Therefore, we tested the effects of PPAR $-\gamma$ agonists on both synovial fibroblast adipogenesis and TNF- $\alpha$-induced IL- 6 and IL- 8 production.

Our results showed that in the limited conditions (DMEM medium supplemented with charcoal-stripped FBS and not by any mixture of adipocyte inducing substances), genistein and rosiglitazone were able to transform synovial fibroblasts into adipocytes characterized by oil-red-stained droplets and adiponectin production. In contrast, the endogen PPAR- $\gamma$ agonist precursor, PGD2, induced the transformation of synovial fibroblasts into adipocytes characterized by sebum-like droplets and leptin production. These results suggested that different PPAR- $\gamma$ agonists may differently induce PPAR $-\gamma^{22}$ Furthermore, we showed that genistein, but not PGD2, downregulated endogenous and TNF- $\alpha$-induced IL- 6 and IL-8. Rosiglitazone, when applied at high concentrations $(50 \mu \mathrm{M})$, had a significant but an inferior inhibitory effect on TNF- $\alpha$-induced IL-6 production compared with genistein, which also inhibited both endogenous and TNF- $\alpha$-induced C/EBP- $\beta$, a transcription factor involved in inflammation ${ }^{23}$ and adipocyte differentiation, ${ }^{24}$ as well as p65 unit of NF- $\kappa \mathrm{B}$. Promoters of IL- 6 and IL- 8 have binding sites for both C/ EBP- $\beta$ and NF- $\kappa \mathrm{B},{ }^{18,19}$ and functional and physical associations between NF- $\kappa \mathrm{B}$ and C/EBP have been shown. ${ }^{25}$ The inhibitory effect of genistein on NF- $\kappa \mathrm{B}$-mediated transcription of IL- 6 has been shown ${ }^{20}$ and we have presented, in this study, that genistein inhibits the binding of C/EBP- $\beta$ on the IL- 8 promoter. These results suggest that genistein inhibits TNF- $\alpha$-induced expression of IL- 6 and IL- 8 through the inhibition of NF- $\kappa \mathrm{B}$ and $\mathrm{C} / \mathrm{EBP}-\beta$ transcription factors. The inhibitory effect of genistein on IL-17-induced IL-8 had already been observed in synovial fibroblasts. ${ }^{26}$ Consequently, genistein has been suggested as a substance that has antiinflammatory potential in the treatment of rheumatic diseases. ${ }^{26,27}$ However, although genistein downregulates TNF- $\alpha$ inflammatory effects, it still cannot induce adipogenesis in the presence of TNF- $\alpha$. These results suggest that TNF- $\alpha$ induced inflammatory and anti-adipogenic pathways are at least partially distinct.

Although genistein enhanced the adipogenesis of osteoprogenitor KS483 cells and mouse bone marrow cells, ${ }^{14,28}$ it is also described as an inhibitor of adipocyte differentiation of mouse 3T3- $\mathrm{L}^{29-31}$ cells. Furthermore, genistein decreased the adipogenic differentiation and maturation of bone marrow stromal cells, and stimulated their differentiation into osteoblasts. $^{32}$ These differences have been explained by the genistein differential effects on ER and PPAR- $\gamma$ pathways. ${ }^{14,28}$ Indeed, the genistein-enhanced osteogenesis of osteoprogenitor KS483 cells is ER-mediated, whereas the genisteinenhanced adipogenesis of osteoprogenitor KS483 cells and mouse-bone marrow cells is PPAR- $\gamma$-mediated. ${ }^{14,28}$ Our results showed that genistein induced adipogenesis in synergy with synthetic PPAR- $\gamma$ agonist, rosiglitazone. This synergy was observed in the number of adipocytes generated, perili-
pin-A production and PPAR- $\gamma 2$ expression. Furthermore, genistein inhibited ERK1/2 phosphorylation, which may consequently inhibit PPAR- $\gamma 2$ phosphorylation, and enhanced adipogenesis, as shown earlier. ${ }^{33}$ In contrast to genistein, $17-\beta$-estradiol had no significant effect on synovial fibroblast adipogenesis, whereas genistein analog and nonactive inhibitor of protein tyrosine kinase, daidzein, had negligible adipogenic activities. These results suggest that genistein-induced adipogenesis in synovial fibroblasts involves PPAR- $\gamma$ induction and protein tyrosine kinase inhibition.

Our results have shown that glucocorticoids stimulated leptin production in synovial fibroblasts. It was shown recently in vivo, in animals and in humans, that glucocorticoidinduced osteoporosis has been linked to leptin production. $^{34,35}$ In view of the known properties of leptin on bone metabolism, it is tempting to speculate that corticosteroid exposure, leptin production and demineralization are linked events. Accordingly, the blockade of the leptin production would be favorable. We have observed that genistein adipogenesis was enhanced markedly by dexamethasone, but genistein downregulated glucocorticoid-induced leptin production in synovial fibroblasts. Furthermore, our results suggest that glucocorticoid-induced leptin production involves the induction of tyrosine phosphorylation, and that genistein downregulated leptin production by its ability to inhibit protein tyrosine kinases. In addition, JAK-2 protein tyrosine kinase inhibitor mimicked the anti-leptin effect of genistein, suggesting that leptin production in synovial fibroblasts involves JAK-2. In rheumatic diseases, leptin is usually considered as a proinflammatory adipokine. In fact, leptin-deficient mice are protected from experimentally induced arthritis, ${ }^{10}$ and protection may include leptin effects on $\mathrm{T}$ cells. ${ }^{36}$ Leptin was shown to be an inducer of nitric oxide in chondrocytes ${ }^{12}$ and of IL- 8 in synovial fibroblasts. ${ }^{13}$ In addition, leptin is produced by chondrocytes in OA. ${ }^{11}$ Finally, an anti-leptin-based approach was proposed for the treatment of inflammatory and autoimmune diseases. ${ }^{37}$ These results suggest that genistein might be beneficial to rheumatic diseases by downregulating leptin.

Although the protective effect of adiponectin on chondrocytes was shown recently, ${ }^{38}$ it was also described that adiponectin enhanced IL-6 production in synovial fibroblasts, involving p38 and NF- $\kappa$ B pathways. ${ }^{39}$ Our results showed that genistein induced adiponectin production but downregulated p38, p65 and IL-6. These results suggest that genistein may downregulate the negative effects adiponectin by inhibiting p38 and NF- $\kappa$ B pathways.

In vivo, PPAR- $\gamma$ ligands have been shown to be effective in several mouse models of inflammation, including arthritis. ${ }^{40}$ Rosiglitazone improved both collagen-induced arthritis ${ }^{41}$ and adjuvant-induced arthritis in mice. ${ }^{42}$ Genistein-treated and collagen II immunized mice showed milder inflammation and joint destruction. ${ }^{43}$ In vitro, we have shown that, unlike rosiglitazone and PGD2, genistein had both adipogenic and 


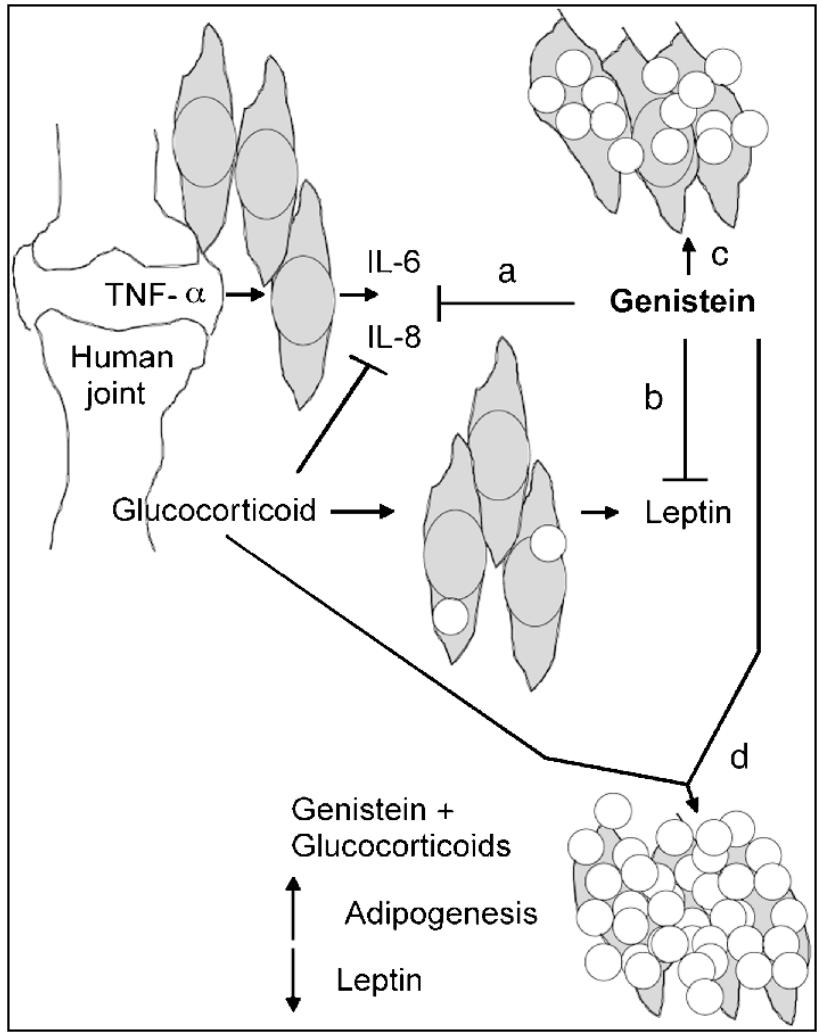

Figure 10 Summary scheme of genistein effects on synovial fibroblasts. In summary, genistein may have several anti-inflammatory effects on synovial fibroblasts: (a) through inhibition of TNF- $\alpha$-induced IL- 6 and IL-8 (Figure $2 c$ and d); (b) through leptin inhibition (Figure 8c); and (c) through the induction of adipogenesis that may per se speed down synovial fibroblast proliferation (Figures 1b and 4a). (d) In addition, in concomitant treatment of synovial fibroblasts with glucocorticoid, genistein enhanced adipogenesis (Figure 4a), and downregulated leptin (Figure 6c), whereas TNF- $\alpha$-induced IL- 6 and IL-8 are further downregulated compared with glucocorticoid effect without genistein (Figure $6 a$ and b).

anti-inflammatory properties on synovial fibroblasts. Furthermore, we have shown that genistein downregulated glucocorticoid-induced leptin production and leptin receptor expression in synovial fibroblasts while having additive antiinflammatory properties. For these reasons, genistein may have a potential for arthritis treatment in association with glucocorticoids or not. A schematic illustration of multiple anti-inflammatory effects of genistein on synovial fibroblasts is shown in Figure 10.

\section{ACKNOWLEDGEMENTS}

We thank Sophie Dubois for her help in flow cytometry analyses and $\mathrm{Dr}$ Henry Van Cauwenberge, Dr Jean-Philippe Hauzeur, Dr Souad Rahmouni, Emilie Théâtre and Monique Henket for their useful discussions. This study was funded by Fonds d'Investissement pour la Recherche Scientifique (FIRS), CHU, Liège, Belgium.

1. van den Berg $W B$, van Lent $P L$, Joosten $L A$, et al. Amplifying elements of arthritis and joint destruction. Ann Rheum Dis 2007;66(Suppl 3):iii45-iii48.
2. Lee DM, Kiener HP, Agarwal SK, et al. Cadherin-11 in synovial lining formation and pathology in arthritis. Science 2007;315: 1006-1010.

3. Jones S, Horwood N, Cope A, et al. The antiproliferative effect of mesenchymal stem cells is a fundamental property shared by all stromal cells. J Immunol 2007;179:2824-2831.

4. Yamasaki S, Nakashima T, Kawakami A, et al. Functional changes in rheumatoid fibroblast-like synovial cells through activation of peroxisome proliferator-activated receptor gamma-mediated signalling pathway. Clin Exp Immunol 2002;129:379-384.

5. De Bari C, Dell'Accio F, Tylzanowski P, et al. Multipotent mesenchymal stem cells from adult human synovial membrane. Arthritis Rheum 2001;44:1928-1942.

6. Yamasaki S, Nakashima T, Kawakami A, et al. Cytokines regulate fibroblast-like synovial cell differentiation to adipocyte-like cells. Rheumatology (Oxford) 2004;43:448-452.

7. Fiorito S, Magrini L, Adrey J, et al. Inflammatory status and cartilage regenerative potential of synovial fibroblasts from patients with osteoarthritis and chondropathy. Rheumatology (Oxford) 2005;44: 164-171.

8. Sakaguchi Y, Sekiya I, Yagishita K, et al. Comparison of human stem cells derived from various mesenchymal tissues: superiority of synovium as a cell source. Arthritis Rheum 2005;52:2521-2529.

9. Koga $H$, Muneta $T$, Ju YJ, et al. Synovial stem cells are regionally specified according to local microenvironments after implantation fo cartilage regeneration. Stem Cells 2007;25:689-696.

10. Busso N, So A, Chobaz-Peclat V, et al. Leptin signaling deficiency impairs humoral and cellular immune responses and attenuates experimental arthritis. J Immunol 2002;168:875-882.

11. Dumond H, Presle N, Terlain B, et al. Evidence for a key role of leptin in osteoarthritis. Arthritis Rheum 2003:48:3118-3129.

12. Otero M, Lago R, Gomez R, et al. Phosphatidylinositol 3-kinase, MEK-1 and p38 mediate leptin/interferon-gamma synergistic NOS type II induction in chondrocytes. Life Sci 2007;81:1452-1460.

13. Tong KM, Shieh DC, Chen CP, et al. Leptin induces IL-8 expression via leptin receptor, IRS-1, PI3K, Akt cascade and promotion of NF-kappaB/ p300 binding in human synovial fibroblasts. Cell Signal 2008;20: 1478-1488.

14. Dang ZC, Audinot V, Papapoulos SE, et al. Peroxisome proliferatoractivated receptor gamma (PPARgamma) as a molecular target for the soy phytoestrogen genistein. J Biol Chem 2003;278:962-967.

15. Dixon RA, Ferreira D. Genistein. Phytochemistry 2002;60:205-211

16. Relic B, Benoit V, Franchimont $\mathrm{N}$, et al. Peroxisome proliferatoractivated receptor-gamma1 is dephosphorylated and degraded during BAY 11-7085-induced synovial fibroblast apoptosis. J Biol Chem 2006;281:22597-22604.

17. Dahl JA, Collas P. MicroChIP_a rapid micro chromatin immunoprecipitation assay for small cell samples and biopsies. Nucleic Acids Res 2008;36:e15.

18. Isshiki H, Akira S, Tanabe O, et al. Constitutive and interleukin-1 (IL-1)inducible factors interact with the IL-1-responsive element in the IL-6 gene. Mol Cell Biol 1990;10:2757-2764.

19. Mastronarde JG, He B, Monick MM, et al. Induction of interleukin (IL)-8 gene expression by respiratory syncytial virus involves activation of nuclear factor (NF)-kappa B and NF-IL-6. J Infect Dis 1996;174:262-267.

20. Vanden Berghe W, Dijsselbloem N, Vermeulen $L$, et al. Attenuation of mitogen- and stress-activated protein kinase-1-driven nuclear factorkappaB gene expression by soy isoflavones does not require estrogenic activity. Cancer Res 2006;66:4852-4862.

21. Akiyama T, Ishida J, Nakagawa S, et al. Genistein, a specific inhibitor of tyrosine-specific protein kinases. J Biol Chem 1987;262:5592-5595.

22. Nolte RT, Wisely GB, Westin S, et al. Ligand binding and co-activator assembly of the peroxisome proliferator-activated receptor-gamma. Nature 1998:395:137-143.

23. Rahman SM, Schroeder-Gloeckler JM, Janssen RC, et al. CCAAT/ enhancing binding protein beta deletion in mice attenuates inflammation, endoplasmic reticulum stress, and lipid accumulation in diet-induced nonalcoholic steatohepatitis. Hepatology 2007;45: 1108-1117.

24. Zuo Y, Qiang L, Farmer SR. Activation of CCAAT/enhancer-binding protein (C/EBP) alpha expression by C/EBP beta during adipogenesis requires a peroxisome proliferator-activated receptor-gamma- 
associated repression of HDAC1 at the C/ebp alpha gene promoter. J Biol Chem 2006;281:7960-7967.

25. Stein B, Cogswell PC, Baldwin Jr AS. Functional and physical associations between NF-kappa B and C/EBP family members: a Rel domain-bZIP interaction. Mol Cell Biol 1993;13:3964-3974.

26. Kehlen A, Thiele K, Riemann D, et al. Expression, modulation and signalling of IL-17 receptor in fibroblast-like synoviocytes of patients with rheumatoid arthritis. Clin Exp Immunol 2002;127: 539-546.

27. Khanna D, Sethi G, Ahn KS, et al. Natural products as a gold mine for arthritis treatment. Curr Opin Pharmacol 2007;7:344-351.

28. Lecka-Czernik B, Moerman EJ, Grant DF, et al. Divergent effects of selective peroxisome proliferator-activated receptor-gamma 2 ligands on adipocyte versus osteoblast differentiation. Endocrinology 2002;143:2376-2384.

29. Hwang JT, Park IJ, Shin Jl, et al. Genistein, EGCG, and capsaicin inhibit adipocyte differentiation process via activating AMP-activated protein kinase. Biochem Biophys Res Commun 2005;338:694-699.

30. Harmon AW, Patel YM, Harp JB. Genistein inhibits CCAAT/enhancerbinding protein beta (C/EBPbeta) activity and 3T3-L1 adipogenesis by increasing C/EBP homologous protein expression. Biochem J 2002;367(Pt 1):203-208.

31. Park HJ, Della-Fera MA, Hausman DB, et al. Genistein inhibits differentiation of primary human adipocytes. J Nutr Biochem 2009;20:140-148.

32. Heim M, Frank O, Kampmann G, et al. The phytoestrogen genistein enhances osteogenesis and represses adipogenic differentiation of human primary bone marrow stromal cells. Endocrinology 2004;145:848-859.

33. Hu E, Kim JB, Sarraf $P$, et al. Inhibition of adipogenesis through MAP kinase-mediated phosphorylation of PPAR- $\gamma$. Science 1996;274:2100-2103.
34. McLaughlin F, Mackintosh J, Hayes BP, et al. Glucocorticoid-induced osteopenia in the mouse as assessed by histomorphometry, microcomputed tomography, and biochemical markers. Bone 2002;30:924-930.

35. Fairbrother UL, Tanko LB, Walley AJ, et al. Leptin receptor genotype at Gln223Arg is associated with body composition, BMD, and vertebral fracture in postmenopausal Danish women. J Bone Miner Res 2007;22:544-550.

36. Matarese G, Leiter EH, La Cava A. Leptin in autoimmunity: many questions, some answers. Tissue Antigens 2007;70:87-95.

37. Matarese G, La Cava A, Sanna V, et al. Balancing susceptibility to infection and autoimmunity: a role for leptin? Trends Immunol 2002;23:182-187.

38. Chen $\mathrm{TH}, \mathrm{Chen} \mathrm{L}, \mathrm{Hsieh} \mathrm{MS}$, et al. Evidence for a protective role for adiponectin in osteoarthritis. Biochim Biophys Acta 2006;1762: 711-718.

39. Tang $\mathrm{CH}$, Chiu YC, Tan TW, et al. Adiponectin enhances IL-6 production in human synovial fibroblast via an AdipoR1 receptor, AMPK, p38, and NF-kappa B pathway. J Immunol 2007;179:5483-5492.

40. Straus DS, Glass CK. Anti-inflammatory actions of PPAR ligands: new insights on cellular and molecular mechanisms. Trends Immunol 2007;28:551-558.

41. Cuzzocrea S, Mazzon E, Dugo L, et al. Reduction in the evolution of murine type II collagen-induced arthritis by treatment with rosiglitazone, a ligand of the peroxisome proliferator-activated receptor gamma. Arthritis Rheum 2003;48:3544-3556.

42. Shiojiri T, Wada K, Nakajima A, et al. PPAR gamma ligands inhibit nitrotyrosine formation and inflammatory mediator expressions in adjuvant-induced rheumatoid arthritis mice. Eur J Pharmacol 2002;448:231-238.

43. Verdrengh $M$, Jonsson $I M$, Holmdahl $R$, et al. Genistein as an antiinflammatory agent. Inflamm Res 2003;52:341-346. 